\title{
PRESENTACIÓN: ¿CORREN (AÚN) BUENOS TIEMPOS PARA EL MICRORRELATO?
}

\author{
Raquel VelázQuez VelázQueZ \\ Universidad de Barcelona \\ raquel_velazquez@ub.edu
}

El interés que especialmente en las tres últimas décadas ha despertado la microficción entre los escritores y escritoras contemporáneos ha desembocado en una verdadera expansión en el siglo XXI de las formas hiperbreves. Esta revalorización de lo que parte de la crítica entiende como un género narrativo independiente, junto a la revitalización desde los años ochenta de la literatura fantástica, ha confluido en la imparable publicación de volúmenes de microrrelatos, tanto individuales como colectivos, en los que la variante fantástica ocupa un puesto central.

El respaldo de lectores, editoriales e investigadores ha contribuido a que la progresión ascendente que desde los años noventa venía caracterizando el desarrollo del microrrelato, y en concreto, su vertiente fantástica, no se haya detenido - ¿está menguando, sin embargo? - cuando estamos entrando ya en la tercera década del presente milenio.

Este monográfico surgió de la voluntad de dar respuesta a preguntas en torno al estado actual del microrrelato fantástico en el ámbito hispánico. ¿Qué tienen en común autores y autoras de microrrelato fantástico de uno y otro lado del Atlántico? ¿Existen diferenciaciones de generación, o de género, o de procedencia geográfica? ¿Cómo siguen explorando los cultivadores del microrrelato fantástico la inestabilidad de lo real? ¿Cómo enfrentan la desautomatización necesaria para seguir rompiendo las expectativas de un lector demasiado familiarizado con los topoi clásicos? ¿Queda aún todavía espacio para la experimentación? ¿Ha traído la cultura del hipertexto innovaciones a nivel formal, estructural, procedimental en el microrrelato fantástico? ¿Tiene fecha de caducidad el microrrelato fantástico o es, por el contra- 
rio, una forma claramente oportuna para este milenio, cuando la realidad parece más inestable que nunca?

Continúan los congresos dedicados a la minificción; existen revistas cuyo objeto de estudio es la minificción en todas sus manifestaciones; abundan los talleres y los concursos literarios de microrrelato, y se sigue publicando no solo producción minificcional, sino recopilaciones de decálogos y poéticas que quieren ser la fórmula para construir buenos micros.

Este interés innegable que despierta la minificción implicaría en consecuencia que todavía le queda vida al microrrelato, pese a que algunos de sus cultivadores actuales lo hayan sustituido, temporalmente o no, por otros géneros; o aunque en ocasiones podamos pensar que todo parece valer mientras sea breve y narre algo. Pero además, convierte en prácticamente imposible que no haya habido intentos anteriores de responder a las preguntas que planteábamos, aunque algunas sigan aún muy parcialmente contestadas. Los trabajos aquí recogidos retoman, pues, ahora los debates y animan a su continuación.

Desgraciadamente, el arranque y desarrollo del presente monográfico en 2020 coincidió con la pandemia que provocó la COVID-19 y, por tanto, con las consecuencias directas o indirectas que tuvo para todos y todas, incluido el confinamiento al que nos forzó la situación sanitaria. Varias colaboraciones que ya estaban comprometidas no pudieron llegar, por lo que quedarán para un futuro, esperamos muy próximo, aquellos trabajos que planteaban un recorrido por el microrrelato fantástico mejicano, peruano, o ecuatoriano, por ejemplo; aquellos que proponían el estudio del tratamiento desde la minificción de un motivo fantástico determinado; o el análisis del uso de recursos tan caros al microrrelato como son la hipertextualidad o la metaficción. Por el momento, contamos afortunadamente con algunas relevantes aproximaciones a las preguntas de las que partía este monográfico por parte de investigadores e investigadoras de reconocida trayectoria en el ámbito de la minificción. Violeta Rojo, además de sus conocidos estudios teóricos sobre esta forma narrativa, nos ha proporcionado visiones de conjunto sobre el microrrelato venezolano; Rony Vásquez Guevara, conocido impulsor del género de la minificción a través de revistas y editoriales, ha firmado varios trabajos diacrónicos y sincrónicos sobre el microrrelato peruano; Laura Pollastri, por su parte, nos ha permitido adentrarnos en la idiosincrasia del relato patagónico; Javier Perucho, a quien debemos varias antologías de microrrelato o estudios tan detenidos como los dedicados a la figura mitológica de la sirena, ha inventariado con mucho rigor los nombres de la minificción en los siglo xx y XXI en México... Podríamos seguir. 
La preocupación por la «forma» del microrrelato; por bautizarlo con una u otra denominación; por ponerle límite de palabras, de párrafos, o de páginas parece haber remitido en la actualidad. Es tanta la bibliografía existente dedicada a dilucidar los rasgos necesarios y contingentes (de primer y segundo nivel de análisis) del microrrelato que, si intentáramos guiar al lector por la más relevante, nos dejaríamos con seguridad algún nombre imprescindible. Esta inclinación hacia el «problema» de la forma habría dejado paso a estudios de carácter temático (la monstruosidad), interdisciplinar (la hipermedialidad), o de género (representaciones de la mujer contada, análisis ginocríticos) por mencionar solo algunas muestras.

Yo misma me he ocupado de ahondar, a partir de corpus minificcional, en los grados y modos de representación de la mujer-personaje, partiendo de la imagen de la mujer mantis o de la muñeca diabólica; he abordado la reescritura de los mitos clásicos; las relaciones entre fantástico y compromiso, y he propuesto un recorrido histórico por el microrrelato español desde sus orígenes hasta la segunda década del siglo XXI, donde además de proporcionar la nómina de los autores y autoras más sobresalientes de la minificción fantástica, identificaba nuevos motivos temáticos a la luz de la evolución de la concepción de lo real, o incidía en los procesos de desautomatización, esenciales para creadores y creadoras que desean seguir sorprendiendo al lector.

Siempre quedan sombras que esclarecer, también en la minificción, y las aportaciones incluidas en este monográfico son nuevas piezas que siguen completando el puzzle de la amplia recepción crítica (ahora ya casi podríamos decir de larga tradición) de esta forma narrativa.

Partiendo de un corpus constituido por seis antologías de microrrelato, publicadas ente 2001 y 2012 en editoriales españolas, Xaquín Núñez Sabarís se plantea en el artículo que abre el monográfico, titulado «Canon y repertorio fantástico en las escritoras de microrrelato», dos objetivos. En primer lugar, se propone identificar cuál es el grado de representación de la mujer escritora en dichas antologías; es decir cuánto está representada en relación con el escritor hombre. En segundo lugar, aborda el análisis textual de los microrrelatos fantásticos de creadoras incluidos en el corpus con el fin de dilucidar qué temas o recursos predominan en ellos.

El hecho de que algunos de los datos de dichas antologías (nombre del autor, o autora, con su nacionalidad y fecha de nacimiento; título del microrrelato y de la antología a la que pertenece) hayan sido vertidos a la base de datos de acceso abierto organizada por el propio autor, y compuesta por 1258 micro- 
rrelatos hispánicos, permite convertir los datos en útiles gráficas que el autor ha incluido en su artículo.

Algunas de las preguntas a las que el lector encontrará respuesta en el artículo de Núñez Sabarís están relacionadas con la presencia cuantitativa de la mujer creadora en el conjunto de las antologías; con cómo se articula esta presencia a la luz de los criterios de selección de los compiladores; o con el tratamiento de lo fantástico por parte de las creadoras.

El bajo porcentaje que corresponde a la presencia de la mujer autora de microrrelato en las antologías no causa sorpresa; en palabras del autor «presenta las mismas características de progresiva visibilidad verificada en otras esferas del campo literario» (Núñez Sabarís, 2021). Por otro lado, el grado de representación es abordado asimismo en el estudio desde el punto de vista generacional, al determinarse una relación de causa-efecto entre el grado de representación de las creadoras y la generación a la que cada una de ellas pertenece. En cuanto al repertorio de temas fantásticos, Núñez Sabarís identifica una serie de concomitancias entre aquellas creadoras pertenecientes a la misma generación. Sostiene igualmente - a raíz de los datos_ que las voces de mujer más contemporáneas son aquellas que están cuantitativamente más representadas, al tiempo que añade, no obstante, que pocas participan en más de una antología.

A las relaciones intermediales entre palabra e imagen dedica Marta Simó-Comas su contribución a este monográfico. Su preciso título, «Interacción creadora entre texto e imagen en el microrrelato fantástico peninsular en las primeras dos décadas del siglo XXI», orienta de forma clara acerca de su punto de partida, al entender la imagen no como un mero acompañamiento decorativo, sino como «texto» que al unirse a otro texto, construye, crea.

Con el fin de ejemplificar distintas posibles combinaciones mediales, la autora analizará con detenimiento las conexiones que se producen entre texto e imagen (esta de distinta naturaleza) en cinco obras de microficción: Cuentos malvados (2010), de Espido Freire, Cuentos del libro de la noche (2005), de José María Merino, Formulaciones tautológicas (2010), de Felipe Benítez Reyes, y Casa de muñecas (2012), de Patricia Esteban Erlés. Simó-Comas añadirá, asimismo, como muestra de transposición medial, el análisis de los mecanismos que propician Ajuar funerario. El cómic: Difuntos, infantes y monstruos (2018), de Imanol Ortiz y Beñat Olea, la adaptación gráfica de una selección de los microrrelatos de la obra que Fernando Iwasaki publicó por primera vez en 2004.

La autora domina el marco teórico del que se provee para llevar a cabo su análisis, que antes de abordar contextualiza oportunamente. Si el microrrelato debe luchar contra la brevedad, dándole por ejemplo la misma importan- 
cia a lo que se dice que a lo que no se dice, la interconexión (la simbiosis semiológica) con la imagen deviene natural, puesto que en cierto modo la imagen también narra.

El objetivo de este segundo trabajo es precisamente explorar esa interacción creadora entre microrrelato e imagen en el contexto de lo insólito. ¿En qué medida el sistema verbal está determinado por el sistema visual y viceversa? Para contestar a esta pregunta Simó-Comas maneja, tomadas de Elleström, las nociones más específicas dentro de la intermedialidad: transmedialidad, multimedialidad o hibridación. Asimismo, a la hora de identificar las combinaciones mediales que le sirven como corpus, parte de Irina Rajewsky (2005), cuando establece dos subcategorías de la intermedialidad literaria: la combinación medial y la transposición medial. A la primera tipología dedica la autora la mayor parte de su trabajo, ya que cuatro de los cinco volúmenes contemplados responden a esa relación dinámica entre los dos ámbitos que entran en contacto, en este caso texto e imagen. Así, en Cuentos malvados, de Espido Freire, existe una subordinación de la imagen respecto al texto, dado que se trata de un añadido posterior; en Cuentos del libro de la noche (2005), de José María Merino, es el mismo autor quien firma los micros y algunas de las representaciones visuales que, en plena complementariedad, incluye el libro; en Formulaciones tautológicas (2010), de Felipe Benítez Reyes, los informes que el autor escribe son verbalización de los collages que también compuso; y en Casa de muñecas (2012) Simó-Comas pone de relieve la estrecha analogía estética entre las creaciones de la escritora, Patricia Esteban Erlés, y las de la ilustradora, Sara Morante.

La segunda tipología o categoría, la transposición medial, por la que se construye un producto nuevo a partir de un original que se ha adaptado o versionado a un lenguaje distinto, la ejemplifica Simó-Comas con ese medio híbrido que es Ajuar funerario. El cómic: Difuntos, infantes y monstruos (2018), que acomete deteniéndose en los mecanismos de la citada transposición.

El estudio pormenorizado de cada uno de estos volúmenes revela a la autora del artículo la simbiosis semiológica que se da entre microrrelato e imagen, que define como un verdadero núcleo de sentido, donde desaparece la relación jerárquica entre las dos artes que entran en contacto.

La tercera contribución al monográfico corre a cargo de la investigadora Marisol Nava Hernández, que analiza la obra minificcional de la escritora mejicana Cecilia Eudave. A pesar de que en un principio no contemplábamos —de acuerdo a los objetivos con los que nació el monográfico- estudios centrados en autores o autoras individuales, decidimos incluirlo porque Cecilia Eudave funciona de símbolo de varias tendencias: la visibilización que pro- 
gresivamente han ido alcanzando las creadoras de microrrelato tanto en el ámbito peninsular como en el hispanoamericano; las amplias posibilidades con las que cuenta lo insólito, que transita por lo fantástico, lo inusual, lo absurdo o lo kafkiano...; o las relaciones de influencia, de colaboración, de camaradería, incluso, que se establecen entre creadores y creadoras de uno y otro lado del Atlántico.

La aportación de Marisol Nava, «Los microrrelatos de Cecilia Eudave: improbables microcolapsos», recorre los volúmenes Para viajeros improbables (2011), y Microcolapsos (2017), este último reeditado por Eolas ediciones en 2019, para identificar, y en cierto modo confirmar, la concurrencia de aquellos rasgos que, desde los primeros trabajos teóricos sobre la minificción, se han identificado como definitorios de esta forma narrativa o este género, según en qué lado del debate nos situemos. Tras analizar de forma panorámica qué rasgos (discursivos, formales y temáticos) se acentúan más en sus microrrelatos, se detendrá en los que para la investigadora son siete de los mejores microrrelatos de Eudave: «Vendas», «Hormigas», «La mascota imaginaria», «Cocodrilocabezas», «La amante del té», «Laberinto» y «De natura», elegidos por Nava Hernández por considerar que en ellos su autora transita por lo fantástico (y no por lo inusual).

El lector no familiarizado con la poética del microrrelato encontrará de gran utilidad la revisión que Nava Hernández elabora a partir de trabajos ya clásicos como los de David Roas, que sirvieron para sistematizar las características del microrrelato: brevedad, narratividad, tramas sencillas, espacio reducido o ausente, escasez de diálogos, poca configuración de los personajes, elipsis, final sorpresivo, etc. La obra minificcional de Cecilia Eudave funcionará como ejemplificación de dicha poética general. En la última parte de su artículo, la autora nos ofrece algunas claves acerca de la trayectoria de Cecilia Eudave en el ámbito de la escritura mínima, al examinar las similitudes y divergencias entre ambos volúmenes de minificción.

Siendo tan distintos, y partiendo de diversos presupuestos, los artículos de Xaquín Núñez, Marta Simó, y Marisol Nava constituyen tres contribuciones inestimables, y complementarias, para seguir entendiendo un poco mejor cuáles son las tendencias actuales en el microrrelato fantástico hispánico. 